
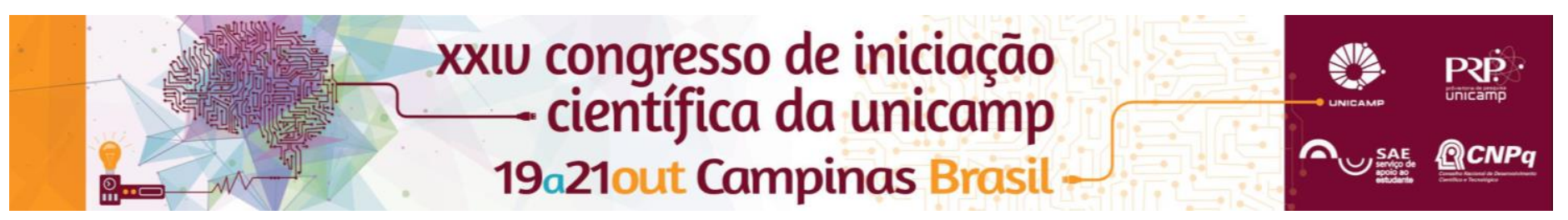

\title{
Análise da valorização imobiliária em Campinas
}

\author{
Eduardo P. Gutiérrez*, Ana Rosa Ribeiro de Mendonça Sarti
}

\begin{abstract}
Resumo
Nos últimos anos, um acentuado crescimento do preço dos imóveis tem sido observado, despertando temores em relação à existência de uma bolha imobiliária no Brasil. A presente pesquisa teve como intuito investigar a existência de uma bolha especulativa no mercado imobiliário na cidade de Campinas, no período compreendido entre os meses de janeiro de 2010 e janeiro de 2014. A análise foi feita por meio da construção dos indicadores de aluguel e preço (IA), e de preço e custo da construção (IC) ${ }^{1}$, com dados dos bairros do Cambuí, Mansões Santo Antonio e Parque Prado, que apresentam intensa atividade imobiliária.
\end{abstract}

\section{Palavras-chave:}

Bolha, imobiliária, Campinas

\section{Introdução}

Este trabalho baseia-se na compreensão das bolhas de ativo sob a ótica keynesiana. Uma bolha se caracteriza pela ocorrência de um ciclo vicioso de demanda em torno de um ativo inicialmente seguro. A demanda valoriza 0 ativo, o que encoraja maior demanda e, consequentemente, valorizações sucessivas, o que aumenta cada vez mais as expectativas dos agentes de valorização do ativo. Esse ciclo faz o preço do ativo se descolar cada vez mais de seus fundamentos, o que aumenta seu risco. Quando os agentes revêem suas expectativas, muitas vezes devido a algum choque exógeno, percebem que estavam descoladas da realidade, e começam a desfazer suas posições imediatamente, em um movimento de manada.

Buscando mensurar 0 estágio de desenvolvimento de uma bolha imobiliária, foram desenvolvidos os indicadores IP, IA e IC, que serão utilizados neste trabalho. O IP mede a diferença entre os preços à vista e de planta, e um valor superior a 1 indica que os agentes possuem expectativas de valorização. O IA é basicamente 0 rendimento que o aluguel representa frente ao preço do imóvel. Reduções desse rendimento não justificadas pela taxa Selic podem indicar aumento da demanda especulativa por imóveis, o que aumenta seu preço de venda sem alterar o preço de aluguel. Por último, temos o IC, que mede a relação entre preço do imóvel e custo. Quando maior que 1, indica um boom da atividade imobiliária, e quando muito maior que 1 , pode indicar bolha imobiliária.

\section{Resultados e Discussão}

Os resultados obtidos estão dispostos na Tabela 1. O indicador IA foi calculado como "Aluguel/Preço do imóvel pronto", e o IC foi calculado como "Preço dos imóveis/Custo da construção civil". O IP não pôde ser calculado devido à escassez de dados referentes ao preço de planta de imóveis, impossibilitando a obtenção de amostras relevantes. O mesmo ocorreu com os dados referentes a apartamentos de 2 dormitórios no Parque Prado, categoria para a qual não obtive amostra relevante. As amostras foram divididas em categorias de imóveis com características semelhantes, de modo a reduzir a variabilidade da amostra e aumentar sua relevância. Além disso, foram calculados os limites estatísticos da amostra com um intervalo de confiança de nível 90\%.
Tabela 1. Indicadores(início e término do período)

\begin{tabular}{|c|r|l|l|l|l|l|r|}
\hline \multicolumn{7}{|c|}{ Indicadores(início e término do período) } \\
\hline \multicolumn{3}{|c|}{} & \multicolumn{2}{|c|}{ Média } & \multicolumn{2}{c|}{ Mínimo } & \multicolumn{2}{c|}{ Máximo } \\
\hline Padrão & Período & IA & IC & IA & IC & IA & IC \\
\hline \multirow{4}{*}{ C-3d d } & jan/10 & $0,37 \%$ & 1,75 & $0,27 \%$ & 1,51 & $0,76 \%$ & 2 \\
\cline { 2 - 8 } & jan/14 & $0,35 \%$ & 2,52 & $0,27 \%$ & 2,23 & $0,99 \%$ & 2,8 \\
\hline \multirow{3}{*}{ C-2d } & jan/10 & $0,71 \%$ & 1,63 & $0,44 \%$ & 1,26 & $1,14 \%$ & 1,99 \\
\cline { 2 - 8 } M-3d & jan/14 & $0,40 \%$ & 2,43 & $0,26 \%$ & 1,84 & $0,63 \%$ & 3,02 \\
\hline \multirow{3}{*}{ M-2d } & jan/10 & $0,57 \%$ & 1,77 & $0,43 \%$ & 1,56 & $0,75 \%$ & 1,98 \\
\cline { 2 - 8 } & jan/14 & $0,37 \%$ & 2,83 & $0,29 \%$ & 2,48 & $0,49 \%$ & 3,19 \\
\cline { 2 - 8 } & jan/10 & $0,69 \%$ & 1,95 & $0,60 \%$ & 1,71 & $0,80 \%$ & 2,19 \\
\hline \multirow{3}{*}{ PP-3d } & $0,34 \%$ & 2,69 & $0,29 \%$ & 2,32 & $0,40 \%$ & 3,06 \\
\cline { 2 - 8 } & jan/10 & $0,34 \%$ & 2,16 & $0,28 \%$ & 1,89 & $0,42 \%$ & 2,44 \\
\hline
\end{tabular}

\section{Conclusões}

Não é possível tirar uma conclusão geral estatisticamente conclusiva. Podemos dizer, com relevância estatística, que houve aumento do IC para apartamentos de 3 dormitórios no Cambuí e de 2 e 3 dormitórios em Mansões Santo Antonio, mas não é um aumento grande o suficiente para podermos afirmar a existência de uma bolha. Porém, podemos verificar uma redução estatisticamente significante do IA referente a apartamentos de 2 dormitórios em Mansões, não justificada por uma redução da Selic, o que indica com bastante clareza a existência de fortes movimentos especulativos na região, típicos de uma bolha imobiliária.

\section{Agradecimentos}

Agradeço à minha orientadora, Ana Rosa Ribeiro de Mendonça Sarti, e ao Correio Popular, por disponibilizar os dados que permitiram a realização dessa pesquisa.

1 Bezerra, M.M.O. et al. Formação, sustentação ou implosão de uma bolha imobiliária? A dinâmica de preços no mercado de imóveis de Natal no período 2005-2010 Disponível em: http://www.scielo.br/pdf/ecos/v22n1/06.pdf $19 / 06 / 2016$ 